STUDI

FRANCESI

\section{Studi Francesi}

Rivista quadrimestrale fondata da Franco Simone

146 (XLIX | II) | 2005

Varia - fasc. II - maggio-agosto 2005

\title{
Jacques \& Marianne Proust, Le Puissant Royaume du Japon
}

Jeannette Geffriaud Rosso

\section{OpenEdition}

Journals

Édition électronique

URL : http://journals.openedition.org/studifrancesi/34141

DOI : 10.4000/studifrancesi.34141

ISSN : 2427-5856

Éditeur

Rosenberg \& Sellier

Édition imprimée

Date de publication : 1 novembre 2005

Pagination : $377-378$

ISSN : 0039-2944

\section{Référence électronique}

Jeannette Geffriaud Rosso, « Jacques \& Marianne Proust, Le Puissant Royaume du Japon », Studi

Francesi [En ligne], 146 (XLIX | II) | 2005, mis en ligne le 01 novembre 2015, consulté le 20 avril 2021.

URL : http://journals.openedition.org/studifrancesi/34141; DOI : https://doi.org/10.4000/

studifrancesi.34141

Ce document a été généré automatiquement le 20 avril 2021.

\section{(c) (i) () $\Theta$}

Studi Francesi è distribuita con Licenza Creative Commons Attribuzione - Non commerciale - Non opere derivate 4.0 Internazionale. 


\title{
Jacques \& Marianne Proust, Le Puissant Royaume du Japon
}

\author{
Jeannette Geffriaud Rosso
}

\section{RÉFÉRENCE}

JACQUES \& MARIANNE PROUST, Le Puissant Royaume du Japon, La description de François Caron (1636). Traduction, introduction \& notes de J. \& M. Proust. Paris, Editions Chandeigne, 2003.

1 On connaît déjà l'intérêt de Jacques Proust pour le Japon ${ }^{1}$. Dans ce nouvel ouvrage, écrit en collaboration avec Marianne Proust, les critiques ont porté leur attention sur un hollandais, François Caron, fils de huguenots français, et publient, de ce dernier, trois textes fort éclairants quant aux moeurs et coutumes japonaises.

2 On ne sait pas grand chose de l'état civil de ce F. Caron (1600-1673). On le suit mieux dans sa carrière qui se déroula entièrement au service des Compagnies de Commerce des Indes Orientales. Engagé d'abord comme simple cuisinier dans la Compagnie hollandaise, il ravit promptement les échelons et en devient le Directeur Général en 1647. Il y restera jusqu'en 1651, date de son retour en Hollande. Après quelques années passées à La Haye, il est distingué par Colbert qui a eu vent de son expérience, de ses grandes compétences dans la conduite de la Compagnie hollandaise et de sa parfaite connaissance de la langue et des moeurs et coutumes japonaises. Pressenti par ce dernier, il se voit offrir, en 1665 , le poste de Directeur Général de la naissante Compagnie de Commerce des Indes françaises. Il restera à son service jusqu'en 1673, date de son retour en France, où il n'aborda point, son bateau ayant coulé et lui avec, au large de Lisbonne.

3 Il a été diversement jugé. D'aucuns ont souligné qu'il avait déjà déplu lors de ses fonctions dans la Compagnie hollandaise et les attaques se firent plus vives encore lors de son passage à la Compagnie française. On ne lui pardonna pas cette «trahison» et les Français eux-mêmes en vinrent à douter de sa loyauté. D'autres jugements, partagés 
semble-t-il par nos critiques, lui sont plus favorables: on loue son ardeur au travail, sa prudence (on le dit homme de bon conseil), sa rigueur de conduite «en toutes choses» et sa fidélité aux précetes de la Religion réformée.

4 J. et M. Proust publient trois textes de F. Caron, dont deux traduits du hollandais par leurs soins. Caron avait rédigé le troisième en français. Non point que les deux premiers textes n'aient jamais connu de version française, il en fut, mais nos critiques ne les ont point retenues, les trouvant trop libres. Quant à celle de Thévenot, de 1664, bien que reconnaissant une certaine élégance de la langue, ils l'ont jugée souvent trop plate ou approximative.

5 Si ces trois textes correspondent à trois périodes bien distinctes de la vie de F. Caron, ils présentent cependant une grande unité tant par leur thème - le Japon - que par le style de l'auteur qui colle à la réalité japonaise qu'il connait bien ayant passé des décennies au Japon, ayant épousé une japonaise et fondé une famille de plusieurs enfants. Un style bien différent de celui des Jésuites portugais traitant du même thème mais qui visaient avant tout à l'évangélisation et de celui des savants, un Kaempfer par exemple, trop pressés par le temps et par un souci d'instruction.

6 La première relation intitulée La Vraie description du puissant royaume du Japon, rédigée en 1636 à Hirado et publiée à La Haye en 1661, était en fait un rapport demandé par le Directeur Général de la Compagnie des Indes qui venait de prendre ses fonctions à Batavia lequel, dans un souci d'information, lui posa 31 questions ciblées sur le Japon, questions auxquelles Caron répondit avec précision, prudence et beaucoup de sensibilité. On y apprend des détails sur la configuration du Japon, sur Sà Majesté l'Empereur de Edo (Tokio) et ses vassaux, sur la façon dont les japonais rendent la justice, sur le culte de l'honneur, sur leur religion et ses sectes, sur leur conception du mariage et l'éducation de leurs enfants, sur la condition féminine, sur leur commerce, etc... C'est sans doute ce récit qui nous renseigne davantage sur les moeurs et coutumes des Japonais. Le Registre journalier de 1639-1641 est, comme son nom l'indique, une sorte de journal que tous les responsables des missions commerciales hollandaises locales devaient tenir à l'intention de leurs supérieurs à Batavia. Plus qu'au détail fastidieux des activités de la factorerie de Hirado (arrivées et départs des vires, inventaire des marchandises importées et exportées - café, thé, sucre, épices, soies et textiles, étain observations météorologique) les critiques ont préféré retenir les récits mettant en scène Caron et ses compagnons dans leurs relations quotidiennes avec leurs partenaires japonais, à Hirado, Nagasaki ou Edo et jusqu'à la Cour. Caron, parfaitement au fait de la réalité japonaise sait se montrer à la fois bon diplomate et fin psychologue, attaché sans doute aux intérêts matériels et moraux qu'il devait défendre, mais aussi très respectueux envers un peuple dont il savait ménager l'extrême susceptibilité. Il s'y fit parmi eux amis et cette sorte de connivence avec certains japonais, lui attira parfois des ennuis au point d'entamer sa crédibilité et de nuire à sa réputation.

Le Mémoire pour Colbert et ses annexes, fut publié la première fois en 1715, dans le Recueil de Voyages au Nord $(. . .)^{2}$. Passé inaperçu parmi ces récits, il prend, inscrit dans la continuité des deux écrits précédents, une toute autre valeur. Rédigé durant la retraite de Caron aux Pays-Bas, il est une somme nostalgique de son expérience du Japon.

8 Il contient des conseils sur le bien-fondé du choix de Mada, car comme entrepôt pour le négoce de la Compagnie, sur les présents à envoyer en Chine et au Japon, afin de s'assurer la bienveillance de ces pays et la liberté de commerce. Caron y fait le détail des denrées à envoyer pour un commencement de négoce. Il précise que visites et 
présents annuels ne se feront pas au nom du Roi mais bien à ceux de ses sujets négociants au Japon. Ces instructions devraient permettre une circulation lucrative des denrées entre France, Chine et Japon. Il va même jusqu'à prêter sa plume au Roi pour un modèle de lettre à envoyer à Sa Majesté l'Empereur de Chine.

9 L'ouvrage est assorti d'une cinquantaine de pages de notes détaillées et fort intéressantes, d'une bibliographie ciblée, d'index géographique et onomastique, d'une douzaine d'illustrations curieuses et éclairantes. On saura gré aux critiques de cet ouvrage inattendu, riche en couleurs, une belle porte ouverte sur le Japon du XVII ${ }^{e}$ siècle.

\section{NOTES}

1. Cf. L'Europe au prisme du Japon, Paris, Albin Michel, 1997 La Supercherie dévoilée, une réfutation du catholicisme au Japon au XVII siècle, Paris, Chandeigne, 1998.

2. Recueil de Voyages au Nord contenant divers mémoires très utiles au commerce et à la navigation, tome III, Amsterdam, J. Frédéric Bernard, 1715. 